\title{
Gradhiva
}

Revue d'anthropologie et d'histoire des arts

$1 \mid 2005$

Haïti et l'anthropologie

\section{Laënnec Hurbon, Religions et lien social : l'Église et l'État moderne en Haïti}

Paris, Éditions du Cerf, 2004, 317 p. bibl.

\section{Rose-Mie Léonard}

\section{(2) OpenEdition}

\section{Journals}

Édition électronique

URL : http://journals.openedition.org/gradhiva/408

DOI : $10.4000 /$ gradhiva.408

ISSN : 1760-849X

\section{Éditeur}

Musée du quai Branly Jacques Chirac

Édition imprimée

Date de publication : 1 mai 2005

Pagination : 265-266

ISBN : 2-915133-08-5

ISSN : 0764-8928

\section{Référence électronique}

Rose-Mie Léonard, «Laënnec Hurbon, Religions et lien social : l'Église et l'État moderne en Haïti »,

Gradhiva [En ligne], 1 | 2005, mis en ligne le 10 décembre 2008, consulté le 21 septembre 2020. URL : http://journals.openedition.org/gradhiva/408 ; DOI : https://doi.org/10.4000/gradhiva.408

Ce document a été généré automatiquement le 21 septembre 2020.

(c) musée du quai Branly 


\title{
Laënnec Hurbon, Religions et lien social : l'Église et l'État moderne en Haïti
}

Paris, Éditions du Cerf, 2004, 317 p. bibl.

\author{
Rose-Mie Léonard
}

\section{RÉFÉRENCE}

Laënnec Hurbon, Religions et lien social : l'Église et l'État moderne en Haïti, Paris, Éditions du Cerf, 2004, 317 p. bibl.

1 Cet ouvrage pose les bases d'une réflexion sur la difficulté de fonder des liens sociaux dans un régime en transition démocratique. Difficulté propre aux pays du tiers-monde où la voie permettant l'établissement d'un État de droit a été ouverte avec la fin des dictatures, mais où en même temps la démocratie peine aujourd'hui à s'installer. Partant de ce constat, l'auteur nous livre un poignant diagnostic du cas haïtien à partir d'une étude originale sur les rapports de l'État avec les religions, notamment la catholique.

2 Unique religion officielle de l'État, à l'exclusion de toutes les autres depuis le Code Noir (1685) et le Concordat (1860), la religion catholique a utilisé son statut privilégié et des voies non démocratiques pour écarter tout autre culte (caraïbes, vodou, francmaçonnerie, protestantisme) de la vie sociale haïtienne. Pourtant, c'est au sein même de l'Église, avec l'action du clergé en faveur des droits de l'homme, que va s'instaurer, pour la première fois, une expérience démocratique. L'État haïtien, né au XIX ${ }^{\mathrm{e}}$ siècle d'une révolution anti-esclavagiste et anti-colonialiste, abolit l'esclavage, mais depuis, cet événement fonctionne en véritable "État de colonisation interne ", révélant ainsi son incapacité et son impuissance à garantir les droits fondamentaux de ses citoyens. Une suite de conflits sombrant dans la violence politique, le despotisme ou la terreur, 
tel est son bilan depuis deux siècles d'indépendance, alors même qu'a toujours existé une forte demande de démocratie de la part de la population.

3 L'Église et l'État ont donc été les deux principales institutions de gestion des conflits dans la société haïtienne : l'Église supplée à l'impuissance de l'État qui en retour lui fournit l'appui nécessaire dans l'exercice de sa mission. Modifiés au cours de leur évolution parallèle et de leurs transformations réciproques, leurs rapports, véritable suite de sérieux malentendus sur deux siècles, ont pourtant historiquement joué un rôle fondamental dans la constitution des liens sociaux en Haïti. La situation actuelle impose la nécessité de refonder le lien social dans un contexte où la démocratie reste « introuvable », le droit difficilement appliqué, l'État défaillant, et le religieux ébranlé dans ses fondements. L'Église et l'État peuvent-ils encore jouer une rôle ? Et lequel ?

Ce sont en ces termes qu'est posé le problème qui justifie une nécessaire (re) fondation de la société haïtienne. Mais sur quelles bases? Encore, faut-il bien saisir que ce problème est essentiellement de nature théologico-politique, manifeste dans l'histoire des relations parfois harmonieuses parfois conflictuelles entre l'État et l'Église pour le contrôle de la société (sa culture, son éducation, son imaginaire).

5 Un grand détour historique s'impose alors, qui permet la compréhension des difficultés actuelles de la démocratie en Haïti. La société haïtienne est façonnée par une double histoire européenne: histoire de violence d'une part, avec la conquête espagnole (extermination des Indiens) et la colonisation française (esclavage des Noirs), histoire d'émancipation d'autre part, avec les idéaux de la Révolution française (liberté, égalité, laïcité) appuyée par l'action de certains hommes d'Église humanistes (l'abbé Grégoire, jésuites solidaires des esclaves). Le problème théologico-politique haïtien a ainsi été pétri dans ce moule, ne fût-ce que dans les formes des relations entre l'Église et l'État : fusion et recoupement durant la colonisation, collaboration et méfiance durant la Révolution, complicités et conflits avant et après la Concordat, harmonisation sous l'Occupation, tensions puis entente sous la dictature, engagement.

6 Il résulte, d'une part, que le lien social haïtien repose historiquement sur une base religieuse et, d'autre part, que le problème de la laïcité n'a jamais préoccupé ni l'église ni l'État. Or, aujourd'hui, l'hégémonie de l'Église est érodée tant par les organisations non gouvernementales (gestion du social) que par les nouveaux mouvements religieux (gestion du spirituel). Une désagrégation du lien social induite par l'absence de repères religieux inspire le besoin d'une refondation qui ne saurait en aucun cas être religieuse (vodou, charismatiques, pentecôtistes).

7 Il est donc nécessaire, affirme l'auteur, de faire du problème de la fondation du lien social haïtien un problème politique pour que sa solution soit sur ce plan, avec pour horizon la laïcité, garantie et assumée par l'État haïtien. Certes, l'hostilité du clergé breton de 1860 à 1950, la non-inscription du principe de laïcité dans les manuels scolaires et dans la Constitution de 1987, l'absence de débats sur ce thème, sont autant de facteurs qui rendent difficile à l'État le choix de la laïcité. D'autant plus que les revendications démocratiques affectent aussi l'ordre politique (détournement de l'aspiration démocratique en populisme avec un prêtre au pouvoir, affaiblissement de l'État). Mais l'État haïtien a intérêt à engager véritablement le pays sur la voie de la démocratie en concevant la laïcité comme lieu d'expression, de fondation et de construction du lien social. Des mesures concrètes? Que l'État investisse les domaines traditionnellement réservés à l'Église, comme l'éducation (enseignement du fait religieux et du vodou à l'école) et la culture (instaurer un débat sur la laïcité). 
8 Riche en informations nouvelles surl'Église et l'État haïtien, conduit suivant une analyse historique originale et une enquête sociologique approfondie, ce dernier livre de Laënnec Hurbon est aussi important que son précédent ouvrage, Le Barbare imaginaire (1988).

\section{AUTEURS}

ROSE-MIE LÉONARD

Rrosemile@aol.com 